\title{
Research on the Basic Mode and Value of the Enterprises Wechat Marketing
}

\author{
Wang Yilong \\ Management System, Handan Polytechnic College, Handan, China, 056001 \\ 59624917@163.com
}

Keywords: Marketing Mode, Marketing Value, Wechat Marketing

\begin{abstract}
With the development of mobile internet technology, Wechat gradually become a necessary smart phone software for the young people. And the increasing hot Wechat marketing has become a weapon in the well-known enterprises' marketing process. This paper firstly introduces the basic concept of Wechat marketing, then describes several common modes of Wechat marketing, and finally gives the important value of Wechat marketingin order to provide some references for the enterprise marketing.
\end{abstract}

\section{Wechat and Wechat Marketing}

Wechat was developed by the Tencent Inc in 2011. By the June 30, 2015, the number of Wechat monthly active users has exceeded 6 hundred million. Wechat quickly monopolys the main intelligent mobile terminal screen with the suddenness of thunder bolt. Most people using smart phones also use the Wechat application. Wechat has super practical and has been deeply involved in all aspects of people's lives.

Wechat is an intelligent terminal to provide instant messaging services for free applications. It supports cross communication operators, cross operating system platform, through the network quickly. At the same time, users can also send free voice, video, images and text through the use of a shared media content data. Based on the position of the social plug-ins lbs, Wechat has the functions of "moments", "sweep the QR code”, "shake”, "drift bottles and public platform plug-in service. Wechat is a convenient instant messaging applications. Among them, the public platform service number, is an account type of the public platform, designed to provide users with services. At an early stage of Wechat, it did not distinguish between private and public numbers, and the number of the public can also be logged on the phone. To meet its more personalized marketing needs, need to have a more powerful background to promote marketing, so Wechat launched a public number. Wechat is a major feature of the Wechat public open platform, the public platform for Wechat marketing system, and gradually become the entire mobile Internet and Internet portal. In addition to the public platform, from the Wechat interface point of view, circle of friends, Wechat group, point to point communication also meet the application of Wechat marketing. Wechat boarded the stage of China's Internet aqueduct becoame the new bestow favor in marketing industry. More and more companies try to develop the marketing tools for greater platform. Wechat marketing value will not be measured.

\section{Basic Mode of Wechat Marketing}

“Moments" Marketing. "Moments" is a Wechat social funcion. The user can publish text and pictures through the "moments" function and articles or music in other software can be shared in the "moments". Users can make a friend's new photos of the "comment" or "praise", the user can only see the same friends comments or praise. Wechat can not only sending graphic information, micro letter users can also through the "moments" to some awesome mobile application and website some attractive content rapid share to their friends, and support to open the link. Users can use a "moments" to the value of information one of the spread of open, able to quickly expand the influence. "Moments" shares the word of mouth marketing provides a good channel. "moments" marketing is business promotion activities in the "moments". Divided into interactive and viral. 
Take the nteractive for example, usesr collect prasies to win prize. Ask a friend to help point to open the link to get the gifts, opening the link on the number of public enterprises and share links, screenshots sent to the public, organic public lottery win awards and so on form. As no matter users collect praises or share links, both of them need a period of time, which can cause sustained attention to the user in the short term. Collecting praises needs to pay attention to the number, users have to share the lottery whichi needs to continue to pay more attention.It may be the number of days after the company announced the results of the lottery. This interval of days also is to have cultured. Enterprises can announce the results of the lucky users to remind the user of the brand again in the period that user have not entirely forgotten the issue.

"Two-dimensional Code" Marketing. Two-dimensional code realize the automatic information recognition through the scaning of the image input device. More and more commercial fileds use the two-dimensional code. Wechat also conform to the trend of the combination of O2O launched commercial activities. The two-dimensional code pattern is placed on the frame, then you will get member discount. Business offers or some news and information, mobile applications to join the two-dimensional code scanning. This o2o mode has already spread, sitting on hundreds of millions of users and active is sufficiently high in the Wechat and value is self-evident, and through scan two-dimensional code form can also increase the number of fans. Two dimensional code is the user to scan the Wechat marketing communication main body of the two-dimensional code and add friends to interact with a marketing approach. After scaning the two-dimensional code, companies often use discounts or coupons and other marketing tools to attract and guide the user consumption. The two-dimensional code marketing is alwasys used in the brand which is doing activities in order to attract part of price sensitive customers.

"Drift Bottle" Marekting. Drift bottle is an application of the QQ mailbox. Since $r$ the introduction of Wechat, drift bottle has also been applied in the Wechat mareketing. Therefore, Wechat can do the brand marketing acitivities by drifting bottle. One is "throw a bottle" and "pick up a bottle". Both of them are simple and convenient. The main marketing can product information written into text messages or released into the voice information will thrown into the sea, potential consumers fishing to drift bottles, according to the wishes of their own can dialogue with the marketing subject. Consumers fishing to relevant product information drift bottles, you can according to their wishes and the subject of marketing communication, the realization of marketing. But each user only twenty times to pick up bottle. Drifting bottle marketing is a random push information way, the propagation of the main active high, the mode of transmission of non directional, spread wide. There is no fixed audience, randomness and flow of information dissemination. As the information acceptance rate and conversion rate is not high, the drift bottle marketing is only suitable for some greater visibility of the product or brand to promote the expansion of the brand influence.

“Offical Accounts” Marketing. Wechat official account provides a professional marketing platform for businesses. Enterprisess can use public platform for consumers to implement point precision marketing customers just add the business of public accounts, as long as the merchant issued a message about the product or store in a public platform, Wechat client can be pushed to the instant message the client mobile phone desktop, mobile phone open as long as the customer can see the relevant information to ensure the accurate marketing enterprises or individual businesses to push customers to send messages of accurate, efficient and timely dissemination of information, the receiving rate and high conversion rate. However, all products have two sides, all businesses should pay attention to push information the frequency, push related products or store information may lead to resentment and discontent over the customer groups. Therefore, Wechat operators to be aware of this and in businesses push information frequency do set as follows. Enterprise class public accounts can only push send a information a month and media public accounts can only send a message a day be. Point to point message has brought a high efficiency of publicity. 


\section{Important Values of Wechat Marketing}

Low Cost. The marketing channels of Wechat marketing are a mobile client. As long as you have a smart phone, you can use the Wechat marketing. Today's popularity of smart phones make us enter the mobile Internet era, and people use Wechat sharing content has not just as a means of communication, has become a way of life. Wechat marketing, compared with other ways of marketing, low cost and convenient. Wechat marketing does not need to be like newspapers, magazines, television, computers, store and so on, such as the entity shop and so on to spend expensive layout fees, advertising fees, rent, etc. It only need you in the Wechat circle of friends or public platform to push information on the product picture or voice, you can push the information to your friends. As a new type of marketing model, Wechat marketing is simple and fast. Wechat marketing and traditional marketing is the biggest advantage compared to the traditional marketing chain of low cost enterprises. Publicity, public relations, sales, sales and other aspects of the need to invest a lot of material and financial resources, and Wechat marketing is avoiding these complex process. The process of Wechat marketing is completed through the network platform, which saves a lot of money.

Fast Dissmination. In the context of the high popularity of mobile internet, business marketing tools have taken fast rhythm mode. Some kind of marketing promotions only last for one or two days, or even less. This fast-paced marketing can let enterprise publicity in a short period of time, reducing the cost of publicity, and conforming to the current user's favorite. Users feel a tension and excitement in a race against time, and participate in this interactive marketing will not take up too many users of time, from the beginning to the end often just a few seconds of operation, in the final results were announced, "snatching" successful achievement feeling is double, if failure did not receive preferential, users will not be too concerned about, because the cost is very small. Wechat instant can give enterprises to provide such a platform for marketing methods, and enrich the means of enterprise marketing. Concern the public platform of fans will be able to receive this information in the first time, this intention powder effect can anytime, anywhere from time or geographical restrictions to and the advertisers have interaction, resulting in consumer behavior. So, in the Wechat marketing, Wechat can not only be the position of the main advertising advertising information, but also can become the first contact with the customer and the customer's first contact and exchange platform. Enterprises only need the Wechat to produce a big ammount of marketing benefits.

Wide Range. The communication form between persons have changed in the mobile internet era. Before the Wechat application apeeared, the interactions between people mostly are the gathering of friends, friends and so on.The traditional way often require people to cost more energy and time and social circle. After the QQ and Renren appeared, people contacting circle expanded, but still be limited. Due to the low threshold for the Internet and authentication is not perfect, interpersonal relationships, mostly floating on surface. Since the emergence of Wechat, it firstly make people who have contacts in the Wechat gathered together from the circle of acquaintances, so that the integrity of the Wechat users to retain the trust of the Wechat. With various forms of information transfer mode. Wechat connects the reality of friends and strangers become a intricate "circle of friends". Trust is the foundation of the marketing success of people and a half. Social acquaintances and strangers, the social interaction that marketing is not like in the complete social acquaintances that is limited, users can easily saturated, and it is difficult to out of the circle to attract more audience, but not like in the complete stranger social circle. The inerrancy of the marketing information will have been questioned in the sranger circle.

High Precision. Wechat marketing realizes the point to point of marketing. Compared to the micoblog, the Wechat application's advantage is obvious. Friends can receive instant pushed letter and dynamic "momoents" in Wechat. When the Wechat suscribes to the public platform, business or personal information on products or services can be directly pushed to the user's mobile phone. With Wechat built-in mobile phone address book synchronization and Tencent QQ plug-in function, it can better and widerly find the target audience groups to push information, including a number of new product information release, enterprise culture information release, holiday promotions 
information publicity and after-sales services such as information service. The point to point of marketing methods ensure the sending accuracy of the information service of the targeted audience. Wechat can subdivide users and realize the accurate positioning. Enterprises firstly contact the demand points and then push the message or give advice in the Wechat marketing.

\section{Conclusion}

Wechat marketing is an innovation of enterprise marketing in the mobile internet era. Wechat marketing can help enterprises to keep pace with the times.With the flexible marketing modes and big markeing value, the Wechat marketing has unlimited potential. All walks of life can enhance corporate brand value and profitability through Wechat marketing.

\section{References}

[1] Li Min, Liu Jiang, On WeChat Marketing Strategy of Businesses Based on SWOT Analysis, J., Journal of North University of China (Social Science Edition), 2015,31(2): 52-56.

[2] Wang Yan, Analysis of Patterns and Prospects of Weixin Marketing, J., Business Economy, 2014(9): 80-82.

[3] Wang Jinglei, The Research of Enterprises' WeChat Marketing and Its Strategy, J., Prices Monthly, 2014(9): 68-71.

[4] Guo Xiaofei, WUBA WeChat Marketing Strategy Research, D., Beijing Jiaotong University, 2015. 